\title{
THE MECHANICAL BEHAVIOUR OF A 25Cr SUPER DUPLEX STAINLESS STEEL AT ELEVATED TEMPERATURE
}

\author{
B. A Lasebikan, A. R. Akisanya ${ }^{1}$ and W.F. Deans \\ School of Engineering, University of Aberdeen, \\ Aberdeen AB24 3UE, U.K.
}

\begin{abstract}
Super duplex stainless steel (SDSS) is a candidate material for production tubing in oil and gas wells and subsea pipelines used to transport corrosive hydrocarbon fluids. The suitability of this material for high temperature applications is examined in this paper. The uniaxial tensile properties are determined for a $25 \mathrm{Cr}$ super duplex stainless steel over a range of temperature relevant to high pressure - high temperature oil and gas wells. It is shown that there is a significant effect of temperature on the uniaxial tensile properties. Elevated temperature was shown to reduce the Young's modulus and increase the strain hardening index; temperature effects on these two parameters are usually neglected in the design of subsea pipelines and oil well tubulars and this could lead to wrong predictions of the collapse pressure. The manufacturing process of the super duplex tubular did not lead to significant anisotropy in the hardness and the ultimate tensile and uniaxial yield strengths.
\end{abstract}

\section{Keywords:}

Stainless steel. Mechanical testing. Environmental performance. Elastic/Plastic behaviour.

\section{INTRODUCTION}

Duplex and super duplex stainless steels are used extensively for various products and components in numerous industries, including refining and petrochemical industry, nuclear power plants and oil and gas industry [1-4]. These alloys are typically categorised

\footnotetext{
${ }^{1}$ Corresponding Author. Email: a.r.akisanya@abdn.ac.uk. Tel.: +44 1224 272989. Fax: +44 1224272497
} 
by their nominal chromium content (e.g. $18 \mathrm{Cr}, 22 \mathrm{Cr}$ and $25 \mathrm{Cr}$ ) and the main alloying elements (e.g. chromium, nickel, molybdenum, nitrogen copper and/or tungsten) which result in different Pitting Resistance Equivalent Numbers (PRENs). The PREN, which is a measure of a material's intrinsic resistance to pitting corrosion, is determined from the element composition (in percentage weight) of the material [5]:

PREN $=\mathrm{Cr}+3.3 \mathrm{Mo}+a \mathrm{~N}$

where $a$ is a constant whose value ranges between 16 and 32 .

Duplex stainless steel (DSS) with PREN greater than 40 are classed as super duplex stainless steel (SDSS). As a general rule of thumb, the higher the PREN, the better the resistance to pitting. The high PREN value of SDSS makes the alloy a candidate material to use in corrosive service environment.

The continuing need for oil and gas exploration and production to satisfy global demand has led to the discovery of new oil and gas fields in high pressure and high temperature (HPHT), Ultra HPHT and Extreme HPHT environments. The pressure and temperature in HPHT reservoirs are up to $69 \mathrm{MPa}(10 \mathrm{kpsi})$ and $149^{\circ} \mathrm{C}\left(300^{\circ} \mathrm{F}\right)$, Ultra HPHT reservoirs are up to $138 \mathrm{MPa}$ (20 kpsi) and $204^{\circ} \mathrm{C}\left(400^{\circ} \mathrm{F}\right)$ and the Extreme HPHT well conditions are up to $207 \mathrm{MPa}(30 \mathrm{kpsi})$ and $260^{\circ} \mathrm{C}(500 \mathrm{oF})$ respectively. The material used for oil and gas production tubing in these challenging environments therefore requires high strength and as well as excellent resistance to corrosion at elevated temperature. SDSS is the material choice in these environments because of the resistance to corrosion due to high PREN [6]. However, the use of SDSS in HPHT environment requires an accurate prediction of the material properties at elevated temperature to determine the appropriate load carrying capacity and to ensure safe design.

Existing design specifications for structural application of steels at elevated temperature, e.g. British Standard BS 5950 Part 8 [7] and European Code 3 Part 1.2 [8], focused on fire protection characteristics of the materials and the temperature-dependent strength 
reduction factors (sometimes referred to as de-rating factors) provided in the standards are based on investigation of carbon steels. Further, design specifications for stainless steel structural members, e.g. European Code 3 Part 1.4 [9], are for stainless steel structures at room temperature. Consequently, many designs involving the use of stainless steels at elevated temperature are based on carbon steel data with the application of a safety factor. This use of carbon steel standards for the design of stainless steel structures at elevated temperature, as it is the case in oil and gas industry, is too conservative and therefore not appropriate as stainless steels exhibit better retention of strength and stiffness at elevated temperature compare to carbon steels.

Previous studies on the elevated temperature effects on the mechanical behaviour of stainless steels have been driven by the need to understand the fire protection characteristics and the resistance to irradiation, for example in nuclear reactors. As a result, majority of these studies have focused on austenitic and martensitic stainless steels which are used more widely in civil engineering structural applications. The uniaxial stress - strain response of various grades of austenitic stainless steels, e.g. AISI 304 and 316 over a wide range of temperature has been reported in literature, see for example, [10-13]. The yield and tensile strengths for austenitic and martensitic stainless steels decrease with increasing temperature (up to $1000^{\circ} \mathrm{C}$ ) with a significant reduction above $400{ }^{\circ} \mathrm{C}$ [10-15]. However, there have been very limited studies on the effect of temperature on the uniaxial tensile properties of duplex steels. The few studies on duplex steels, which have also been driven by the need for fire safety, are on 22Cr DSS (i.e. SAF 2205 or EN 1.4462); 22Cr DSS has been shown to have better strength retention than austenitic stainless steels up to 300 ${ }^{\circ} \mathrm{C}$, and worst strength retention between 300 and $1000^{\circ} \mathrm{C}[14,16]$. The requirements for fire resistant structures where the temperature could be as high as $1000{ }^{\circ} \mathrm{C}$ and for a very short duration are different from those of long service industrial applications where the temperature are much lower (less than $300^{\circ} \mathrm{C}$ ) and for much longer duration. Surprisingly, most of the previous studies on elevated temperature effects on 25Cr DSS have been on the precipitation of secondary phases during material processing and welding, see, for example, $[17,18]$. The long service industrial application of SDSS, in particular the $25 \mathrm{Cr}$ SDSS, requires detailed understanding of the in-service effect of elevated temperature on 
the mechanical properties to enable a better utilization of this grade of stainless steel in challenging environments typical of high pressure-high temperature oil and gas wells.

The material properties of a $25 \mathrm{Cr}$ SDSS, such as the $0.2 \%$ proof stress, Young's modulus and ultimate tensile stress, at room and elevated service temperature are determined in this paper. The experimental results are used to assess the implications of the strength and stiffness reduction for the design of downhole production tubulars used in HPHT oil and gas wells and in subsea pipelines.

\section{EXPERIMENTAL PROCEDURES}

\subsection{Material and specimen preparation}

The material considered in this study was a cold-worked Grade 125 super duplex stainless steel (SDSS). This was obtained in tubular form with 7" (177.8 mm) outside diameter and $14 \mathrm{~mm}$ wall thickness. The material has a chemical composition primarily based on $25 \mathrm{wt} \%$ chromium, 7 wt\% nickel and 3 wt\% molybdenum, i.e. Group 2, Category 25-7-3 per ISO 13680 standard [19] for corrosion resistant alloy (CRA) tubing. The full details of the chemical composition are provided in Table 1. The element composition gives a PREN in the range 40 to 42 (see eqn (1)), which is consistent with the minimum PREN for SDSS.

The main tests carried out were: hardness test and uniaxial tensile test at elevated temperature.

\section{Metallography and Hardness Specimens}

A number of specimens with cross sectional dimensions of $5 \mathrm{~mm}$ by $4 \mathrm{~mm}$ were machined from the SDSS tubing in the transverse - radial plane (referred to as T-R) and longitudinal - radial plane (referred to as L-R) for metallographic examination and hardness measurements, as shown in Figure 1. The longitudinal direction is parallel to the rolling direction. The metallographic examination and hardness measurements were carried out at different locations across the wall thickness of the pipe following a $3 \times 3$ grid pattern. 
The location of the metallographic and hardness examination are referred to by IL, IM, IR for the path nearer the inner surface, by ML, MM, MR for the path at mid thickness and OL, OM, OR to the path near the outer surface of the pipe (see Figure 1). Three specimens were examined for each of the $\mathrm{T}$ and $\mathrm{L}$ planes; these specimens are identified as $\mathrm{T} 1, \mathrm{~T} 2, \mathrm{~T} 3$ and L1, L2, L3.

The metallographic specimens were embedded in phenolic powder and closed die compacted at $150{ }^{\circ} \mathrm{C}$ for 5 minutes. The surface of the specimen was then, abraded to 240 grit, using a grinding wheel, polished with 6 and $0.05 \mu \mathrm{m}$ diamond pastes and cleaned in deionised water and acetone. Thereafter the specimens were chemically etched in $90 \mathrm{ml}$ distilled water and $10 \mathrm{ml} \mathrm{HCl}$ at $70{ }^{\circ} \mathrm{C}$ for 5 minutes. The hardness specimens were prepared in the same manner as those used for metallographic examination.

The microstructure and phase composition were analysed with optical microscope and scanning electron microscope (SEM) using the back scattered electron signal (BSE) analysis. Further quantitative metallographic studies were also performed with optical microscope using Omnimet Advantage Image Analysis toolbox (supplied by Buehler) to quantify the volume fraction of ferrite and austenite in the microstructure. The determination of the volume fraction in this manner is consistent with the automatic point counting method of ASTM E1245-03 [20].

\section{Uniaxial Tensile Specimens}

Uniaxial tensile specimens were machined from the transverse and longitudinal directions of the SDSS tubular to assess the level of anisotropy in the material's tensile properties. The specimens were solid circular cylinder, with a gauge length of $33 \mathrm{~mm}$ and $5 \mathrm{~mm}$ diameter (see Figure 2). The ends of specimens were threaded for ease of connection to the loading fixtures. Coolant was used for all cutting and machining processes to minimise the effect of the heat associated with the machining on the mechanical properties and microstructure. 


\subsection{Testing Procedure}

\subsubsection{Hardness}

The hardness was measured using Vicker's microhardness tester, in the T-R and L-R planes following the $3 \times 3$ grid pattern shown in Figure 1. The hardness was measured at mid thickness and at $2 \mathrm{~mm}$ from the inner and outer surfaces of the pipe; and at locations spaced at $4 \mathrm{~mm}$ along longitudinal and transverse direction (Figure 1). Three specimens were examined for each of the T-R and L-R planes; these specimens are identified as TR1, TR2, TR3 and LR1, LR2, LR3. The hardness measurements were subsequently converted to Rockwell C (HRC) equivalent values using the standard Vicker's conversion table for easy comparison with the designation used in a number of design standards e.g. ISO 15156 [6].

\subsubsection{Uniaxial tension}

Two high temperature strain gauges, type QFLA-52, suitable for temperatures up to $200{ }^{\circ} \mathrm{C}$ were positioned diametrically opposite each other and set up so as to eliminate bending strains from the measured axial strain. Dummy gauges were used to counteract temperature effects on the measured axial strain. Tensile tests were carried out in displacement control and at a different crosshead speed of $0.5 \mathrm{~mm} / \mathrm{min}$ using screw-driven Instron testing machine. The crosshead speed is equivalent to a nominal strain rate of $2.5 \times 10^{-4} \mathrm{~s}^{-1}$. The load and the strains were continuously recorded using a computerised data logger. The tensile tests were performed at room temperature and at elevated temperatures: 90, 110 and 160 and $200{ }^{\circ} \mathrm{C}$. An environmental chamber mounted on the testing machine was used to heat up the samples to the required temperature as indicated on the chamber's digital temperature display. A thermocouple (T type connected to a handheld digital thermometer MM2030 temperature range -200 to $400{ }^{\circ} \mathrm{C}$ ) was also attached to the surface of the specimen to ensure it was at the required temperature during the test. Load was applied after the required temperature was achieved. At least two specimens were tested at each of the temperatures considered.

\footnotetext{
${ }^{2}$ Manufactured by Tokyo Sokki Kenkyujo Co. Ltd
} 


\section{Results and Discussion}

\subsection{Phase balance and microstructure.}

A metallographic examination of a number of samples showed that the SDSS contained a duplex ferrite and austenite microstructure after chemical etching. A typical micrograph is shown in Figure 3. As expected, the ferrites are elongated in the cold-worked direction (i.e. the longitudinal direction). No deleterious phases, e.g. sigma $(\sigma)$ and chi $(\chi)$, were detected but some dark spots were observed randomly in the microstructure mainly in the austenite phase and at the grain boundaries. This dark spots though suspected to be chromium nitride $\left(\mathrm{Cr}_{2} \mathrm{~N}\right)$ were not investigated as it is beyond the scope of the current study. It is important to note that nine metallographic examinations were conducted at different locations within each of the three nominally identical samples in the transverse and longitudinal directions; see Table 2. The structure and distribution of the ferrite and austenite in the micrographs shown in Figure 3 are typical of all the examinations.

The volume fraction of the two phases was determined using the image analysis software. Individual phases in the micrographs are colour coded and the surface area fraction (which is approximately equal to the volume fraction) of each phase is then determined in accordance with ASTM E1245 [20]. The typical result shown in Figure 4 suggests 47\% volume fraction of the ferrite and $53 \%$ for the austenite. A summary of the phase composition for all the specimens tested is given in Table 2: the volume fraction of the ferrite ranged from 40 to $54 \%$ while that of the austenite ranged from 44 to $55 \%$. The average volume fraction was found to be $49 \%$ for the ferrite and $51 \%$ for austenite. The average values are not dependent on the direction (transverse or longitudinal), see Table 2 .

Cold-worked duplex stainless steels used as downhole tubulars in oil and gas industry usually have a ferrite content volume fraction of between $35 \%$ and $65 \%$ [6]. Prouheze et al. [21] found the optimum mechanical and corrosion resistance properties are obtained for a phase proportion of 1:1 for cold-worked and solution annealed DSS, as found in the SDDS grade considered in the current investigation. However, Hagen and Keller [22] 
found austenitic content ranging between 40 and $60 \%$ to be most favourable for the corrosion chemical properties of DSS tubes.

\subsection{Hardness}

The hardness measured near the inner and outer surfaces and at mid-wall thickness of the parent pipe are summarised in Table 3. The change in hardness is very small for each of the samples in the transverse and longitudinal planes. The measured hardness in the transverse and longitudinal planes was in the range of 32 to 35HRC. The measured value of the hardness is within the maximum value of 36HRC recommended by NACE [6] in order to minimise the susceptibility of the material to environment assisted cracking.

\subsection{Uniaxial tensile stress - strain response}

The stress - strain response at room temperature is shown in Figure 5 for three nominally identical specimens in the longitudinal and transverse directions. The repeatability and consistency of the tests is demonstrated by the relatively small difference between the stress-strain responses for three nominally identical specimens. The stress - strain curve follows a typical linear, non-linear response for a cold worked-steel where the nonlinearity is quantified by the degree of strain hardening.

The Young's modulus, yield strength (defined here as the stress at which the stress-strain response changes from linear to nonlinear), the $0.2 \%$ proof stress, and the tensile strength determined from the experimental data are summarised in Table 4. There is insignificant difference in the measured values of these properties in the longitudinal and transverse directions, i.e. no noticeable anisotropy. This is consistent with the results of the hardness measurement presented in Table 3 . The measured values of the material uniaxial properties are in agreement with those recommended for cold worked SDSS grade 125 per the ISO standard for corrosion resistant alloy (CRA) tubing [19]. However, various researchers [23 - 26] have highlighted that all cold worked duplex stainless steel have a degree of anisotropy in their strength properties. The cold work process induces residual strain in the material that may result in unequal magnitude of yield stress in the transverse and longitudinal directions. This is due to the varying structural configurations of the 
individual manufacturing conditions [22]. The degree of anisotropy depends on the processing route, i.e., the sequence of cold work and annealing as well as the deformation methodology. It has been shown that the anisotropy developed during cold work is usually negligible so long as the total cold work strain is not too large, for example less than 30 per cent rolling [27]. The authors have no information regarding the cold work strain of the parent pipe. The lack of or negligible level of anisotropy in the uniaxial tensile properties and hardness determined for this material would suggest the cold work strain is less than $30 \%$.

The uniaxial test was also carried out at 90, 110 and 160 and $200{ }^{\circ} \mathrm{C}$ in the longitudinal and transverse directions. The effect of temperature on the stress - strain response is shown in Figure 6. The stress - strain response at elevated temperature is qualitatively similar to that at room temperature. The measured values of the uniaxial tensile properties are however dependent on the temperature. The effect of temperature on the tensile strength and the $0.2 \%$ proof stress is shown in Figure 7 ; and the temperature dependency of all the measured tensile properties are summarised in Table 5. It is noted that the strength of the material decreased as the temperature increased. Similarly like in the room temperature tests, there was no significant anisotropy at elevated temperature. The strength in the transverse direction was slightly lower at the same test temperature, compared to longitudinal direction, as the temperature increased. The measured property in the transverse direction at a given temperature differ by a maximum of about $2 \%$ of the corresponding value in the longitudinal direction, with the maximum difference occurring at higher temperature $\left(\geq 160^{\circ} \mathrm{C}\right)$. The Young's modulus decreased from a value of $207 \mathrm{GPa}$ at room temperature to $191 \mathrm{GPa}$ at $200{ }^{\circ} \mathrm{C}$; a $8 \%$ reduction.

The cold-worked state is a condition of higher internal energy. Residual stresses arise due to plastic deformation which may not be uniform throughout the entire cross section of the part been deformed. Cold work results in an increase in strength and decrease in ductility that is achieved with intermediate annealing operations and a final cold working step to the required strain to achieve the specified strength. This may be followed by stress relief to reduce residual stresses generated by non uniform plastic deformation from the 
manufacturing operation. Residual stresses are usually alleviated by heating to a specified temperature that does not result in a change in microstructure and mechanical properties. There should be no observable change in the physical properties and microstructure of the cold-worked SDSS subject to heating at less than $300{ }^{\circ} \mathrm{C}$. At higher temperatures, phases which affect the corrosion resistance, for example $\alpha^{\prime}$ (also known as $475^{\circ} \mathrm{C}$ embrittlement) and secondary austenite i.e. $\gamma_{2}\left(600-700{ }^{\circ} \mathrm{C}\right)$, can form $[17,18]$. The properties that are most affected by temperature are those which are sensitive to point defects that is responsible for nearly all aspects of plastic deformation. Thus the strength properties which are controlled by dislocation are usually affected by increase in temperature. As temperature increases, thermal activation assists in the formation of vacancies thus the required stress to cause slip during plastic deformation decreases. As the strength of the material comes from cold working, increasing the temperature relaxes the material, resulting in reduced mechanical properties, as observed in the current study.

The observed reduction in the tensile strength of the SDSS material between ambient temperature $\left(22^{\circ} \mathrm{C}\right)$ and $90^{\circ} \mathrm{C}$ in the longitudinal direction was $115 \mathrm{MPa}$ and a decrease of $55 \mathrm{MPa}$ was observed between 90 and $250^{\circ} \mathrm{C}$. Similarly the $0.2 \%$ proof stress decreased by $89 \mathrm{MPa}$ between ambient temperature and $90^{\circ} \mathrm{C}$ and by $73 \mathrm{MPa}$ between $90^{\circ} \mathrm{C}$ and $200{ }^{\circ} \mathrm{C}$. These results are consistent with those of Prouheze et al. [21] who found a decrease of around $100 \mathrm{MPa}$ at $100{ }^{\circ} \mathrm{C}$ and $150 \mathrm{MPa}$ at $300^{\circ} \mathrm{C}$ in the $0.2 \%$ proof stress for the VS22 (22Cr) grade of cold worked SDSS, which is different from the 25Cr SDSS considered in the current study.

The effect of temperature on the $0.2 \%$ proof stress is more pronounced than the effect on tensile strength. From the results shown in Figure 7, the temperature dependence of the tensile strength (UTS) and the $0.2 \%$ proof stress $\left(\sigma_{0.2}\right)$ can be fitted, within the temperature range of $22-200^{\circ} \mathrm{C}$, to the following equations:

$$
\text { UTS }=0.0048\left(T^{2}\right)-2.014(T)+1099.3
$$




$$
\sigma_{0.2}=0.004\left(T^{2}\right)-1.7745(T)+1003.3
$$

where $T$ is the temperature in ${ }^{\circ} \mathrm{C}$; and both UTS and $\sigma_{0.2}$ are in MPa.

\section{IMPLICATIONS FOR THE DESIGN OF SUBSEA PIPELINES AND OIL AND GAS PRODUCTION TUBULARS}

It is common in casing, tubing and pipeline design in the oil and gas industry to assume the Young's modulus is not temperature dependent. The experimental results presented above suggest a reduction of up to $8 \%$ in the modulus at an elevated temperature of $200{ }^{\circ} \mathrm{C}$. If this is not adequately accounted for in the design of oil well casing, tubing and subsea pipelines made from Grade 125 SDSS, it could result in over estimation of elastic collapse pressure for the pipe; a major design consideration in pipeline design in deep water applications.

Designers routinely use room-temperature mechanical properties with a safety factor to account for temperature effects, or alternatively use the strength value at the operating temperature. The latter is usually referred to in many pipeline design codes (e.g. DNV [28], API [29]) as the stress de-rating factor, defined as the ratio between the strength at the operating temperature and the corresponding strength at room temperature. Existing design standard for stainless steels [9] only covers ambient temperature applications. The stress de-rating factor for the SDSS grade considered in this study is shown in Figure 8, based on the average measured strengths. The stress de-rating increased with increasing temperature. There is a reduction of about $16 \%$ in both the UTS and the $0.2 \%$ proof stress at $200{ }^{\circ} \mathrm{C}$. Recall that the upper temperature limit for ultra high pressure and high temperature oil and gas well is about $204{ }^{\circ} \mathrm{C}$. The results presented in this chapter will enable the appropriate design safety factor to be determined for this grade of material in both HPHT and ultra HPHT applications.

The $0.2 \%$ proof stress de-rating factor for $22 \mathrm{Cr}$ DSS and for austenitic stainless steel AISI 304 [14] are compared with the results obtained in the current study in Figure 8. The de- 
rating factor for the $22 \mathrm{Cr}$ is comparable to that of the $25 \mathrm{Cr}$ DSS considered in this paper. However, the $25 \mathrm{Cr}$ DSS retain more strength than the austenitic stainless steel; this therefore makes the 25Cr DSS more suitable for HPHT applications.

In order to allow some level of non-linear plastic deformation while avoiding the onset of instability (i.e. necking), subsea pipelines and casing design codes usually specify that the ratio between the $0.2 \%$ proof stress and the tensile strength must be in the range,

$$
0.75 \leq \frac{\sigma_{0.2}}{U T S} \leq 0.95
$$

This is used as one of the criteria for material selection for oil casing, tubing and subsea pipelines. The greater the ratio $\sigma_{0.2} / \mathrm{UTS}$ the smaller the uniform plastic deformation the material can sustain before the onset of instability which can subsequently lead to burst for pipelines and tubulars subject to internal overpressure. The values of $\sigma_{0.2} /$ UTS for the grade of SDSS was found to vary between 0.89 to 0.93 over the range of temperature $22^{\circ} \mathrm{C}$ to $200{ }^{\circ} \mathrm{C}$ considered in this study. This is within the range recommended by design codes $[28,29]$. Therefore the SDSS (grade 125) tubing is suitable for production tubing in oil and gas wells and subsea pipelines.

The stress - strain response at room temperature and elevated temperature can be fitted to the power law equation

$$
\sigma_{t}= \begin{cases}E \varepsilon_{t} & \varepsilon_{t}<Y / E \\ K \varepsilon_{t p}^{n} & \varepsilon_{t}>Y / E\end{cases}
$$

where $\sigma_{t}$ and $\varepsilon_{t}$ are the true stress and true strain, $E$ is the Young's modulus, $K$ is the plastic strength coefficient, $n$ is the strain hardening index and $Y$ is the yield stress. 
The nominal stress $\sigma$ and nominal strain $\varepsilon$ presented in Figures 5 and 6 are related to the true stress $\sigma_{t}$ and true strain $\varepsilon_{t}$ by

$$
\sigma_{t}=\sigma(1+\varepsilon) ; \quad \varepsilon_{t}=\ln (1+\varepsilon)
$$

The strain hardening index, $n$, and the coefficient $K$ are usually determined from the slope and intercept of the $\log \varepsilon_{t p}$ versus $\log \sigma_{t}$ plot over a chosen stress range in the interval $Y<$ $\sigma<\sigma_{\text {UTS }}$. The accuracy of the values of $n$ and $K$, obtained using this approach (referred to here as method 1) depends on the chosen stress range and choice of the line of best fit to the experimental data. These factors could lead to significant error in the calculated values for $n$ and $K$.

By imposing the condition of constant volume during plastic deformation and that the maximum load is attained when $\sigma=\sigma_{U T S}$ it can easily be shown that for a uniaxial tensile test, the strain hardening index $n$ and stress coefficient $K$ are given by [30]

$$
\begin{aligned}
& n=\ln \left(1+\varepsilon_{\text {UTS }}\right) \\
& K=\left(\frac{2.71}{n}\right)^{n} \sigma_{U T S}
\end{aligned}
$$

where $\varepsilon_{U T S}$ is the nominal strain when $\sigma=\sigma_{U T S}$. The use of (7) and (8) to determine $n$ and $K$ is referred to here as method 2. This method gives more accurate result as it does not involve any curve fitting. The values of the strain hardening index $n$ and strength coefficient $K$ of the material under investigation at different temperature are shown in Table 6, for both methods 1 and 2 .

The strain hardening index $n$ determined by method 1 decreased with increasing temperature, while that determined using method 2 decreased between room temperature 
and $110^{\circ} \mathrm{C}$ but increased thereafter. The decrease in the strain hardening in method 1 may be due inherent errors in curve fitting. We note that the strain hardening index determined by method 2 is greater than that by method 1 by between 10 and $20 \%$. The difference in the strength coefficient by the two methods is less than $5 \%$.

The strain hardening index results presented in Table 6 show that the index obtained by both methods 1 and 2 only vary between about 0.016 and 0.03 . The strain hardening index $n=0$ for perfectly plastic solid. Thus the SDSS used in this study could be assumed to have a very mild strain hardening characteristics over the range of temperature considered. The room temperature strain hardening index is normally used in the design of downhole tubular and subsea pipelines. The results shown in Table 6 shows a slight temperaturedependence of the strain hardening index and it would therefore be appropriate to use the strain hardening to characterise the deformation of the material under consideration up to a temperature of $200^{\circ} \mathrm{C}$.

\section{CONCLUSIONS}

The uniaxial tensile properties have been determined for a $25 \mathrm{Cr}$ (Grade 125) SDSS over a range of temperature relevant to high pressure - high temperature oil and gas wells. It is shown that there is a significant effect of temperature on the uniaxial tensile properties, with the properties decreasing with increasing temperature. Elevated temperature was shown to reduce the Young's modulus and the strain hardening index; temperature effects on these two parameters are usually neglected in the design of subsea pipelines and oil well tubulars and this could lead to wrong predictions of the elastic and plastic collapse pressure. The results presented above will allow a better and safer design of oil and gas

production tubulars and subsea pipelines. Despite the cold work involved in the manufacture of the SDSS tubular, there was insignificant anisotropy as determined from both the hardness measurements and also the uniaxial tensile and yield strengths. This implies the level of cold work in the pipe is very low. 


\section{Acknowledgements}

The authors acknowledge the experimental assistance of Stuart Herbert, Alastair Robertson, Derek Logan, and Jim Gall of the University of Aberdeen, School of Engineering Central Workshop. BAL acknowledges the financial support of Shell Exploration and Production (UK).

\section{REFERENCES}

[1] M. Holmquist, Duplex stainless steels avoid damage in hydrocarbon processing, Energy Processing Canada, 95; 2002, p 5-8.

[2] J. Olsson and M. Snis, Duplex - A new generation of stainless steels for desalination plants, Desalination, 205; 2007; p 104-113.

[3] M. Veljkovic and J. Gozzi, Use of duplex stainless steel in economic design of a pressure vessel, Trans ASME J Pres Vess Tech, 129; 2007, p 155-161.

[4] I.N. Bastos, S.S.M. Tavares, F. Dalard, and R.P. Nogueira, Effect of microstructure on corrosion behavior of super duplex stainless steel at critical environment conditions, Scripta Materialia, 57; 2007, p 913-916.

[5] H. Hanninen, J. Romu, R. Ilola, J. Tervo, and A. Laitinen, Effects of processing and manufacturing of high nitrogen-containing stainless steels on their mechanical, corrosion and wear properties, J Mater Proc Tech, 117; 2001, p 424-430.

[6] NACE MR0175/ISO 15156, Petroleum and Natural Gas Industires - Materials for use in $\mathrm{H}_{2} \mathrm{~S}$-containing Environments in Oil and Gas Production, 2005. NACE MR0175/ISO 15156.

[7] BS 5950-8, Structural use of steelwork in building - Part 8: Code of practice for fire resistant design. British Standard BS5950-8, 2003. 
[8] Eurocode 3, Design of steel structures - Part 1.2: General - Structural fire design. Brussels: European Committee for Standardization. BS EN 1993-1-2.

[9] Eurocode 3. Design of steel structures - Part 1.4: General - Structures in stainless steels. Brussels: European Committee for Standardization. BS EN 1993-1-4.

[10] J.W. Kim and T.S. Byun, Analysis of tensile deformation and failure in austenitic stainless steels: part 1 - temperature dependence, J Nuclear Mater, 396; 2010, p 1-9.

[11] T.S. Byun, N. Hashimoto, and K. Farrell, Temperature dependence of strain hardening and plastic instability behaviors in austenitic stainless steels, Acta Mater, 52; 2004, p 3889-3899.

[12] C.R. Brinkman, Elevated temperature mechanical properties of an advanced type 316 stainless steel, Trans ASME J. Pres Vessel Tech, 123; 2001, p 75-80.

[13] L. Gardner and K.T. Ng, Temperature development in structural stainless steel sections exposed to fire, Fire Safety Journal, 41; 2006, p 182-203.

[14] J. Chen and B. Young, Stress-strain curves for stainless steel at elevated temperatures, Eng Struct, 28; 2006, p 229-239.

[15] A.K. Roy, S.R. Kukatla, B. Yarlagadda, V.N. Potluri, M. Lewis, M. Jones, and B.J. O'Toole, Tensile properties of martensitic stainless steels at elevated temperatures, J Mater Eng Performance, 14; 2005, p 212-218.

[16] L. Gardner, A. Insauti, K.T. Ng, and M. Ashraf, Elevated temperature material properties of stainless steel alloys, J Constructional Steel Res, 66; 2010, p 634-647.

[17] M. Martins and L.C. Casteletti, Sigma phase morphologies in cast and aged super duplex stainless steel, Mater Charact, 60; 2009, p 792-795.

[18] D. Dyja and Z. Stradomski, Microstructural evolution in duplex cast steel after quench ageing process, Arch Mater Sci Eng, 28; 2007, p 557-564. 
[19] ISO 13680:2000(E). Petroleum and natural gas industries - Corrosion-resistant alloy seamless tubes for use as casing, tubing and coupling stock - Technical delivery conditions. 2000. ISO.

[20] ASTM E1245-03. Practice for determining the inclusion or second phase constituent content of metals by automatic image analysis. ASTM 2008.

[21] J.C. Prouheze, J.C. Vallant, G. Guntz, and Lefebvre, Production of tubing in duplex steel VS22 - Influence of cold working on mechanical properties behaviour in corrosive sour gas and oil Environment, Duplex Stainless Steels Conference Proceedings, (St. Louis, Missouri), 1983, p 247-265.

[22] I.V. Hagen and M. Keller, Interrelation Between Fabrication Processes and Mechanical Properties of AF 22 Duplex Tubes. Duplex Stainless Steels Conference Proceedings, (St. Louis, Missouri), 1983, p 325-353.

[23] W. Zheng and D. Hardie, Effect of structural orientation on the susceptibility of commercial duplex steels to hydrogen embrittlement, Corrosion, 47; 1991, p 792-799.

[24] G. Herbsleb and R.K. Poepperling, Corrosion Properties of Austenitic-Ferritic Duplex Steel AF 22 in Chloride and Sulfide Containing Environments, Corrosion, 36(11); 1980, p 611-618.

[25] M. Oberndorfer, K. Thayer, and M. Kastenbauer, Application limits of stainless steels in the petroleum industry, Materials and Corrosion-Werkstoffe Und Korrosion, 55; 2004, p 174-180.

[26] J.L. Song and Bate, Plastic anisotropy in a superplastic duplex stainless steel, Acta Materialia, 45; 1997, p 2747-2757.

[27] J. Hill The Mathematical Theory of Plasticity, Oxford, The Clarendon Press, 1950, p 267-269.

[28] DNV. Submarine Pipelines Systems, Offshore Standard DNV- OS-F101. 2007. 
[29] API . Specification for casing and tubing. API Specification 5CT. $6^{\text {th }}$ ed. 1998.

[30] F.J. Klever and G. Stewart, Analytical burst strength prediction of OCTG with and without defects, Proceeding of the SPE Applied Technology Workshop on Risk Based Design of Well Casing and Tubing, 7-8 May 1998, (The Woodlands, Texas, USA), SPE 48329. 


\section{LIST OF TABLES}

Table $1 \quad$ Chemical composition (percent by weight) of the pipe material

Table 2 Phase balance of the SDSS microstructure in the longitudinal-radial plane (L1, L2, and L3) and in the transverse-radial plane (T1, T2 and T3).

Table 3 Rockwell C Hardness values in (a) Longitudinal (L) and (b) Transverse (T) directions.

Table $4 \quad$ Uniaxial tensile properties in the transverse (T) and longitudinal (L) directions at room temperature

Table 5 Uniaxial tensile mechanical properties in the transverse (T) and longitudinal (L) directions at elevated temperatures.

Table 6 Effect of temperature on strain hardening index $n$ and strength coefficient $K$. 


\section{LIST OF FIGURES}

Figure 1 Location of measured hardness and metallographic examination in the transverse - radial $(\mathrm{T}-\mathrm{R})$ and longitudinal - radial $(\mathrm{L}-\mathrm{R})$ planes. All dimensions in millimetres.

Figure 2 (a) Orientation of the uniaxial tensile sample, and (b) Photograph of the tensile sample.

Figure 3 Super duplex stainless steel microstructure. The dark colour is the ferrite while the grey/white colour is the austenite.

Figure 4 Phase balance analysis. (a) Microstructure before phase analysis; dark (ferrite) and white/grey (austenite). (b) The microstructure after the phases have been colour coded. (c) Area fraction analysis of the ferrite phase. (d) Area fraction analysis of the austenite phase.

Figure 5 Uniaxial stress - strain response at room temperature, $\sim 22{ }^{\circ} \mathrm{C}$.

(a) Longitudinal direction and (b) Transverse orcircumferential direction.

Figure 6 Effect of temperature on the uniaxial stress - strain response (a) Longitudinal direction and (b) Transverse direction. Two nominally identical specimens tested are identified by letters A and B after the test temperature.

Figure 7 Effect of temperature on the tensile strength (UTS) and $0.2 \%$ Proof Stress (PS) in the longitudinal (L) and transverse (T) directions. 
Figure 8 Effect of temperature on the strength de-rating factor, i.e. ratio of the strength UTS or $0.2 \%$ PS at temperature and the value of the corresponding strength at room temperature. The best fit to the experimental data is shown as continuous and dash-dash lines. 
Table 1: Chemical composition of the pipe material

\begin{tabular}{|c|c|c|c|c|c|c|c|c|c|c|c|}
\hline \multicolumn{10}{|c|}{ Chemical Composition (wt\%) } \\
\hline $\mathbf{C}$ & $\mathbf{S i}$ & $\mathbf{M n}$ & $\mathbf{P}$ & $\mathbf{S}$ & $\mathbf{C u}$ & $\mathbf{N i}$ & $\mathbf{C r}$ & $\mathbf{M o}$ & $\mathbf{W}$ & $\mathbf{C o}$ & $\mathbf{N}$ \\
\hline 0.02 & 0.036 & 0.049 & 0.028 & $<0.015$ & 0.49 & 6.83 & 24.5 & 3.27 & 2.61 & 0.11 & 0.32 \\
\hline
\end{tabular}


Table 2: Phase balance of the SDSS microstructure in the longitudinal-radial plane (L1, L2, and L3) and in the transverseradial plane (T1, T2 and $\mathrm{T} 3$ ).

\begin{tabular}{|c|c|c|c|c|c|c|c|c|c|c|c|c|}
\hline \multirow{2}{*}{ Sample } & \multirow{2}{*}{ Phase } & \multicolumn{3}{|c|}{ Outer surface (\%) } & \multicolumn{3}{|c|}{ Mid-wall (\%) } & \multicolumn{3}{|c|}{ Inner surface $(\%)$} & \multicolumn{2}{|c|}{ Average (\%) } \\
\hline & & OL & $\mathbf{O M}$ & OR & ML & MM & MR & IL & IM & IR & Ferrite & Austenite \\
\hline \multirow{2}{*}{$\mathrm{L} 1$} & Ferrite & 53.2 & 49.5 & 54.1 & 49.4 & 44.9 & 47.4 & 49.4 & 50.5 & 50.8 & \multirow{6}{*}{$49.3 \pm 3.9$} & \multirow{6}{*}{$50.9 \pm 3.8$} \\
\hline & Austenite & 46.9 & 50.6 & 46.0 & 50.7 & 54.8 & 52.8 & 50.7 & 49.6 & 49.2 & & \\
\hline \multirow{2}{*}{$\mathrm{L} 2$} & Ferrite & 54.9 & 52.0 & 49.0 & 49.7 & 45.4 & 40.1 & 49.7 & 46.4 & 43.6 & & \\
\hline & Austenite & 45.3 & 48.4 & 51.2 & 50.4 & 54.7 & 60.1 & 50.4 & 53.7 & 56.5 & & \\
\hline \multirow{2}{*}{ L3 } & Ferrite & 47.4 & 54.8 & 50.4 & 50.3 & 53.8 & 45.1 & 45.4 & 47.1 & 56.2 & & \\
\hline & Austenite & 52.8 & 45.3 & 49.7 & 49.8 & 46.3 & 55.0 & 54.7 & 53.0 & 44.1 & & \\
\hline \multirow{2}{*}{$\mathrm{T} 1$} & Ferrite & 50.3 & 50.3 & 50.1 & 46.9 & 49.5 & 51.3 & 49.6 & 50.5 & 50.8 & \multirow{6}{*}{$49.4 \pm 1.8$} & \multirow{6}{*}{$50.8 \pm 1.8$} \\
\hline & Austenite & 49.9 & 49.9 & 50.1 & 53.3 & 50.9 & 48.8 & 50.5 & 49.2 & 49.3 & & \\
\hline \multirow{2}{*}{$\mathrm{T} 2$} & Ferrite & 48.5 & 47.6 & 49.7 & 47.7 & 53.5 & 48.7 & 50.2 & 52.1 & 51.1 & & \\
\hline & Austenite & 51.6 & 52.5 & 50.4 & 52.5 & 46.7 & 51.5 & 49.9 & 48.0 & 50.5 & & \\
\hline \multirow{2}{*}{$\mathrm{T} 3$} & Ferrite & 45.7 & 46.9 & 49.8 & 47.9 & 48.3 & 49.1 & 49.2 & 46.8 & 51.4 & & \\
\hline & Austenite & 54.4 & 53.2 & 50.3 & 52.3 & 51.8 & 51.0 & 50.9 & 53.4 & 48.8 & & \\
\hline
\end{tabular}


Table 3 - Rockwell C Hardness values in (a) Longitudinal (L) and (b) Transverse (T) directions.

(a) Longitudinal (L) direction

\begin{tabular}{|c|c|c|c|c|c|c|c|c|c|}
\hline Location & \multicolumn{3}{|c|}{ Outer surface } & \multicolumn{3}{c|}{ Mid wall } & \multicolumn{3}{c|}{ Inner Surface } \\
\hline Specimen & OL & OM & OR & ML & M & MR & IL & IM & IR \\
\hline LR1 & 33.8 & 31.6 & 34.3 & 34.3 & 33.3 & 32.5 & 31.6 & 35.3 & 31.6 \\
\hline LR2 & 33.3 & 31.6 & 33.3 & 31.6 & 35.2 & 32.5 & 32.5 & 32.0 & 33.3 \\
\hline LR3 & 31.6 & 31.6 & 33.3 & 34.3 & 33.3 & 33.3 & 32.5 & 31.6 & 31.6 \\
\hline Average & \multicolumn{3}{|c|}{$32.7 \pm 1.1$} & \multicolumn{3}{|c|}{$33.4 \pm 1.1$} & \multicolumn{3}{c|}{$34.2 \pm 1.2$} \\
\hline
\end{tabular}

(b) Transverse (T) direction

\begin{tabular}{|c|c|c|c|c|c|c|c|c|c|}
\hline Location & \multicolumn{3}{|c|}{ Outer surface } & \multicolumn{3}{c|}{ Mid wall } & \multicolumn{3}{c|}{ Inner Surface } \\
\hline Specimen & OL & OM & OR & ML & M & MR & IL & IM & IR \\
\hline TR1 & 34.3 & 35.3 & 34.3 & 33.3 & 34.3 & 35.3 & 34.3 & 33.1 & 31.6 \\
\hline TR2 & 33.3 & 34.3 & 36.3 & 31.6 & 35.2 & 35.2 & 34.3 & 36.1 & 33.3 \\
\hline TR3 & 31.6 & 33.3 & 33.0 & 35.2 & 35.2 & 34.3 & 33.3 & 33.3 & 31.6 \\
\hline Average & \multicolumn{3}{|c|}{$34.0 \pm 1.4$} & \multicolumn{3}{|c|}{$34.4 \pm 1.3$} & \multicolumn{3}{c|}{$33.4 \pm 1.2$} \\
\hline
\end{tabular}


Table 4: Uniaxial tensile properties in the transverse (T) and longitudinal (L) directions at room temperature

\begin{tabular}{|l|c|c|c|c|c|c|c|c|}
\hline $\begin{array}{l}\text { Tensile } \\
\text { Samples }\end{array}$ & T1 & T2 & T3 & L1 & L2 & L3 & \multicolumn{2}{|c|}{ Average } \\
\hline$\sigma_{\mathrm{Y}}(\mathrm{MPa})$ & 601.3 & 619.7 & 591.1 & 596.2 & 600.4 & 606.4 & $\begin{array}{c}604 \\
\pm 14.5\end{array}$ & $\begin{array}{c}601 \\
\pm 5.2\end{array}$ \\
\hline$\sigma_{0.2}(\mathrm{MPa})$ & 936.7 & 975.4 & 954.5 & 967.1 & 970.6 & 969.7 & $\begin{array}{c}956 \\
\pm 19.4\end{array}$ & $\begin{array}{c}969 \\
\pm 1.8\end{array}$ \\
\hline $\mathrm{UTS}(\mathrm{MPa})$ & 1055.9 & 1079.2 & 1056.2 & 1060.8 & 1069.7 & 1057.7 & $\begin{array}{c}1064 \\
\pm 13.4\end{array}$ & $\begin{array}{c}1063 \\
\pm 6.3\end{array}$ \\
\hline$E(\mathrm{GPa})$ & 207.0 & 207.2 & 206.2 & 209.9 & 205.7 & 208.4 & $\begin{array}{c}207 \\
\pm 0.5\end{array}$ & $\begin{array}{c}208 \\
\pm 2.2\end{array}$ \\
\hline
\end{tabular}


Table 5 - Uniaxial tensile mechanical properties in the transverse (T) and longitudinal (L) directions at elevated temperatures.

\begin{tabular}{|c|c|c|c|c|c|c|c|c|c|c|c|c|c|c|}
\hline Temperature & \multicolumn{4}{|c|}{$90^{\circ} \mathrm{C}$} & \multicolumn{4}{|c|}{$11^{\circ} \mathrm{C}$} & \multicolumn{4}{|c|}{$160^{\circ} \mathrm{C}$} & \multicolumn{2}{|c|}{$200^{\circ} \mathrm{C}$} \\
\hline Orientation & L1 & L2 & T1 & T2 & L1 & L2 & T1 & T2 & L1 & L2 & T1 & T2 & L1 & T1 \\
\hline$\sigma_{\mathrm{Y}}(\mathrm{MPa})$ & 607.4 & 593.7 & 571.9 & 584.7 & 493.2 & 567.2 & 528.9 & 546.0 & 414.3 & 574.3 & 424.1 & 427.7 & 589.8 & 511.5 \\
\hline$\sigma_{0.2}(\mathrm{MPa})$ & 879.9 & 881.8 & 840.3 & 842.3 & 848.7 & 852.8 & 806.7 & 822.5 & 829.6 & 812.1 & 764.4 & 781.8 & 807.4 & 766.4 \\
\hline UTS (MPa) & 947.4 & 948.5 & 936.2 & 938.9 & 933.1 & 936.7 & 926.2 & 938.9 & 892.3 & 884.1 & 875.1 & 878.5 & 904.6 & 904.6 \\
\hline$E(\mathrm{GPa})$ & 205.9 & 208.4 & 205.6 & 205.5 & 200.5 & 201.3 & 201 & 194.8 & 196.1 & 198.6 & 195.3 & 199.7 & 196.3 & 185.8 \\
\hline
\end{tabular}


Table 6 - Effect of temperature on strain hardening index $n$ and strength coefficient $K$.

\begin{tabular}{|c|c|c|c|c|}
\hline \multirow{2}{*}{$\begin{array}{c}\text { Temperature } \\
(\mathbf{O} \mathbf{C})\end{array}$} & \multicolumn{2}{|c|}{$n$} & \multicolumn{2}{c|}{$K$ (MPa) } \\
\cline { 2 - 5 } & Method 1 & Method 2 & Method 1 & Method 2 \\
\hline 22 & 0.0287 & 0.0270 & 1219.3 & 1204.1 \\
\hline 90 & 0.0203 & 0.0245 & 1051.8 & 1062.7 \\
\hline 110 & 0.0201 & 0.0218 & 1038.1 & 1037.0 \\
\hline 160 & 0.0157 & 0.0298 & 974.7 & 1031.9 \\
\hline
\end{tabular}




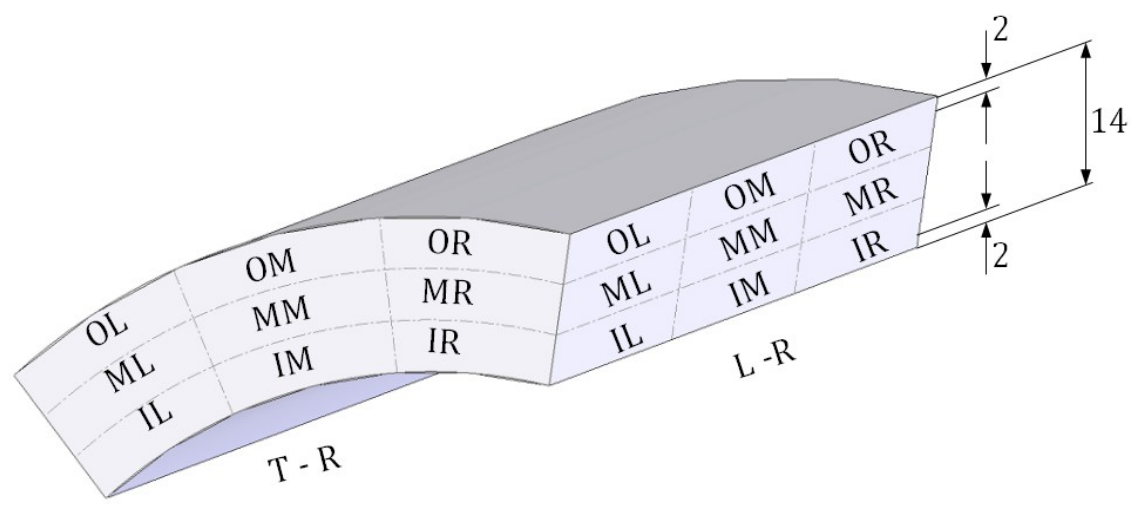

Figure 1: Location of measured hardness and metallographic examination in the transverse - radial $(\mathrm{T}-\mathrm{R})$ and longitudinal - radial $(\mathrm{L}-\mathrm{R})$ planes. All dimensions in millimetres. 


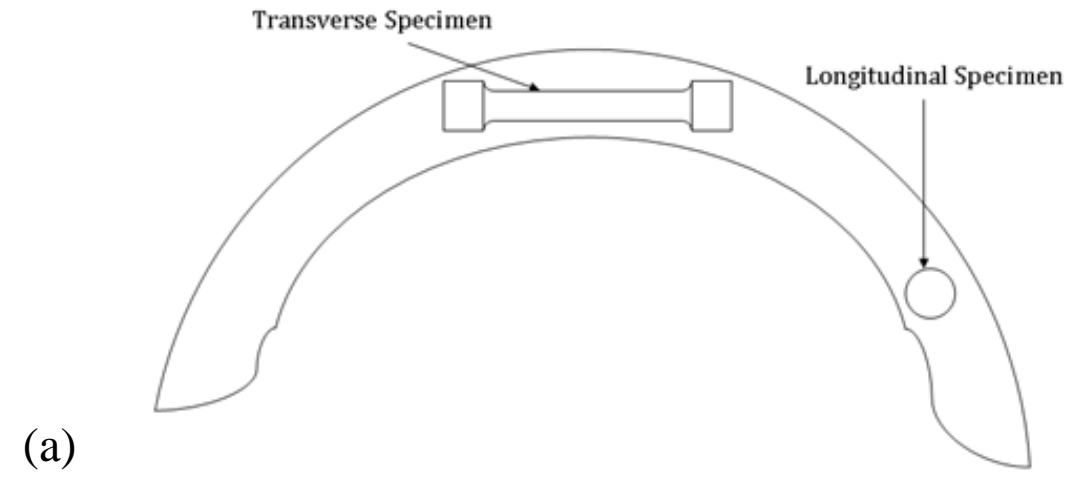

(a)

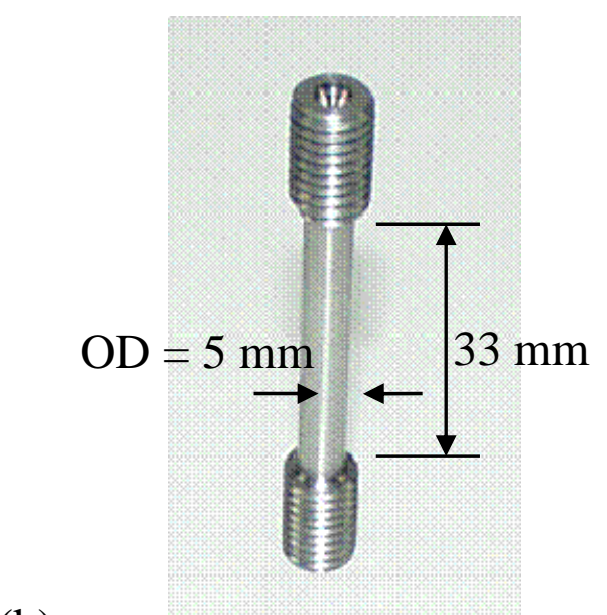

(b)

Figure 2: (a) Orientation of the uniaxial tensile sample and (b) photograph of the tensile sample. 


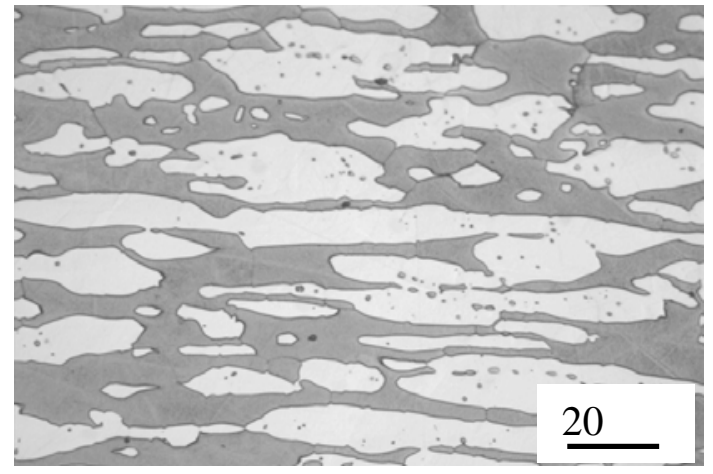

(a) Longitudinal orientation

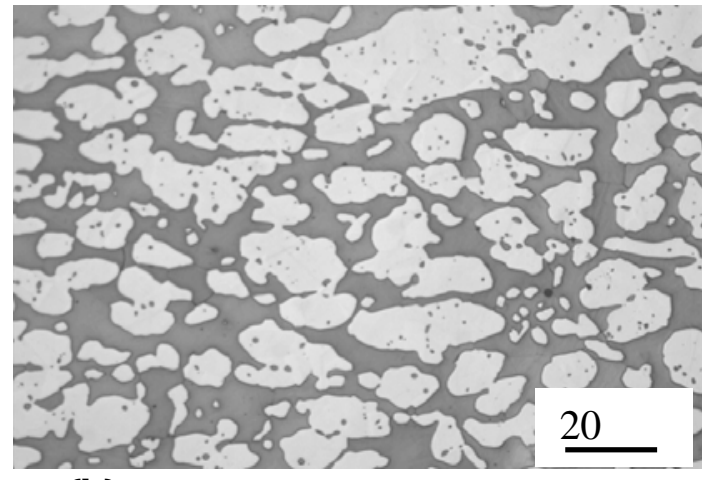

(b) Transverse orientation

Figure 3 Super duplex stainless steel microstructure. The dark colour is the ferrite while the grey/white colour is the austenite. 


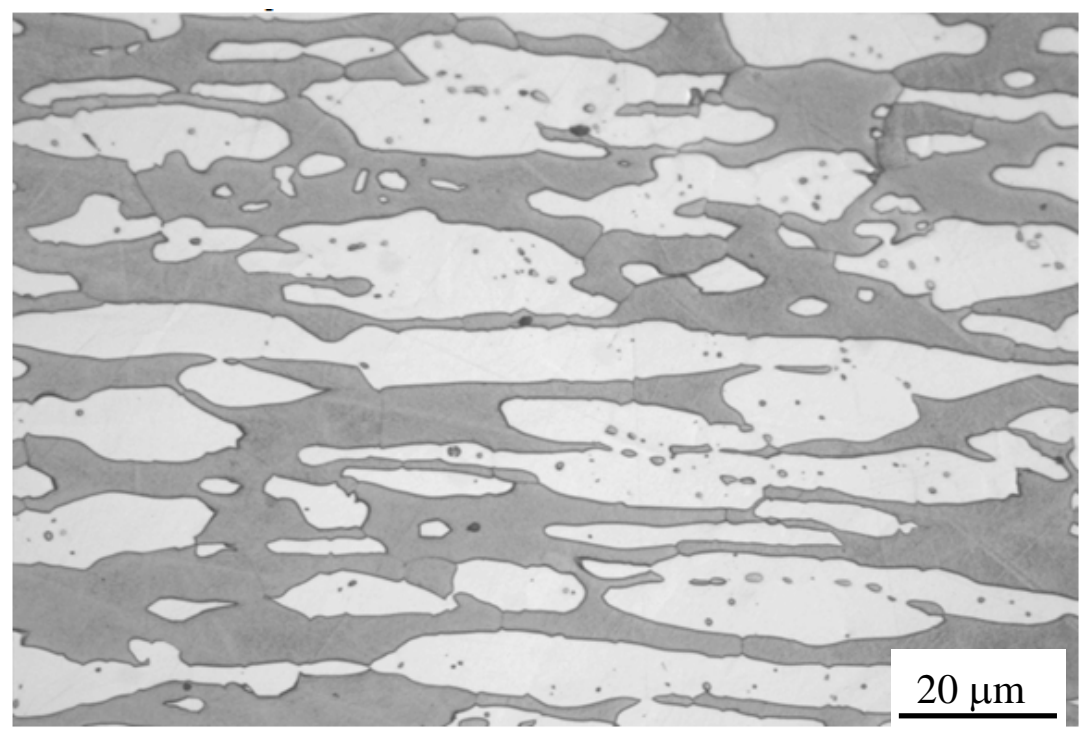

(a)

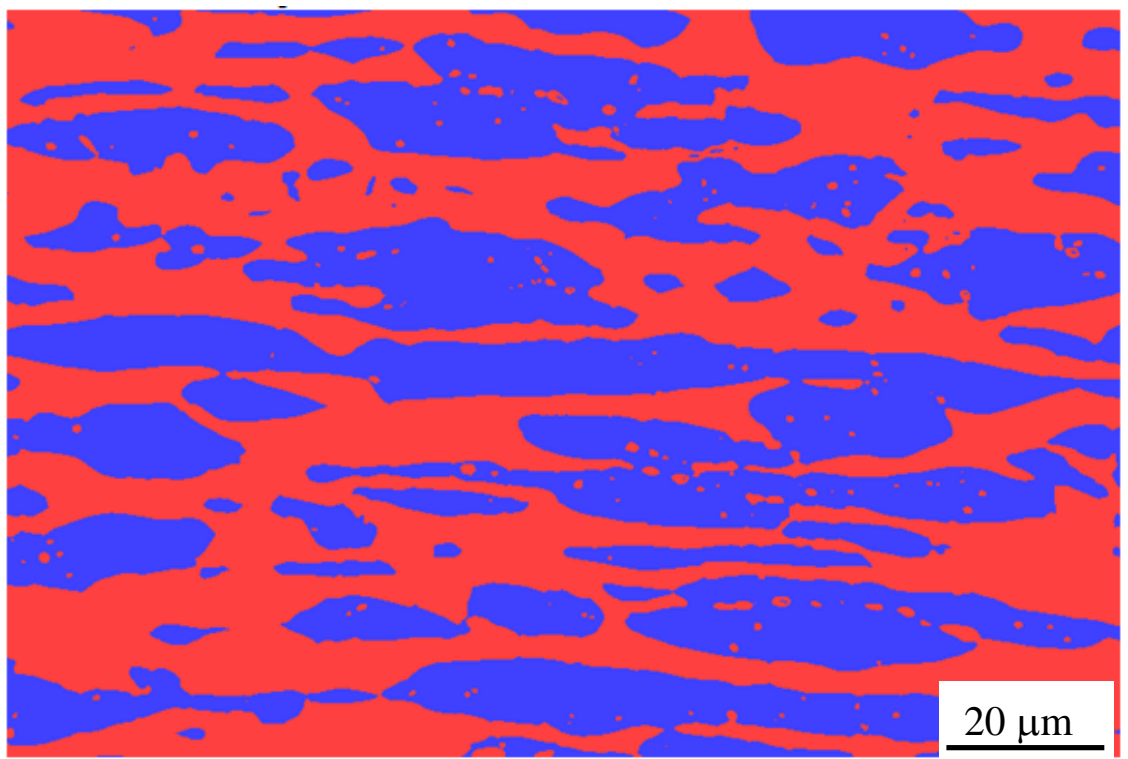

(b) 


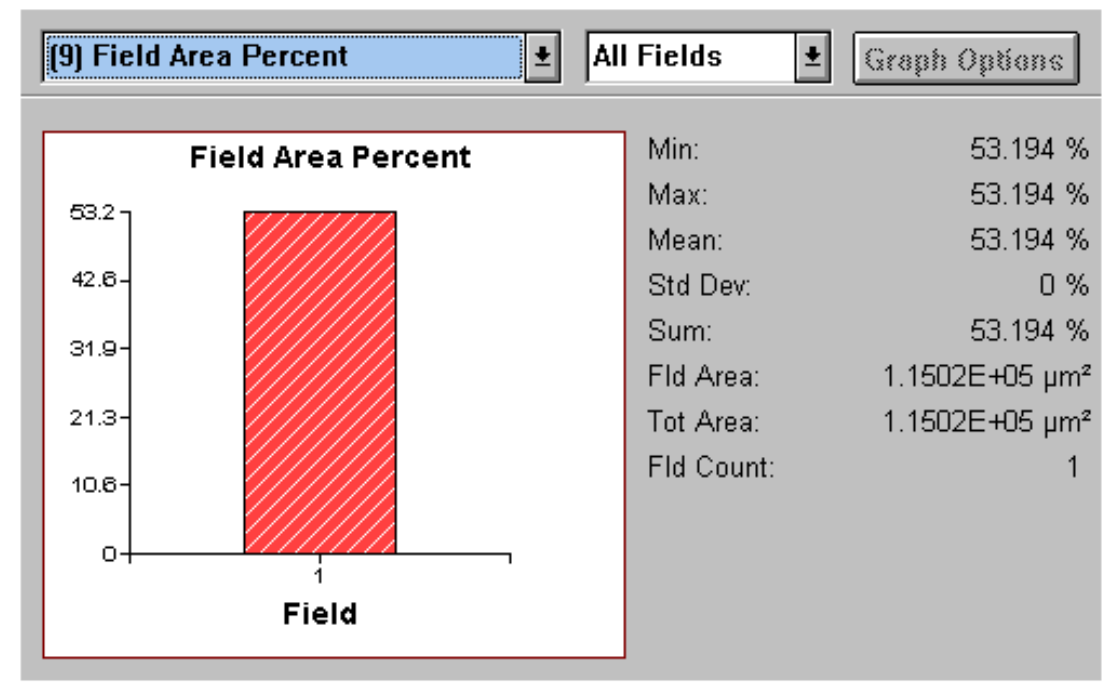

(c)

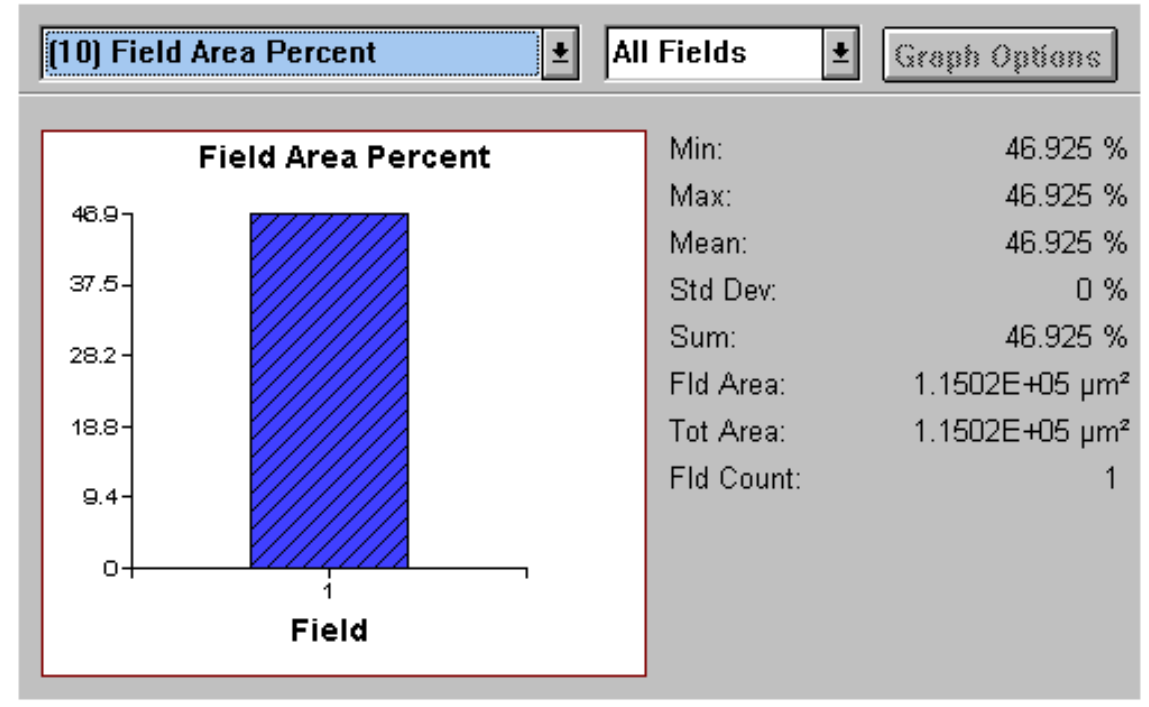

(d)

Figure 4 Phase balance analysis. (a) Microstructure before phase analysis; dark (ferrite phase) and white/grey (austenite phase). (b) The microstructure after the phases have been colour coded. (c) Area fraction analysis of the ferrite phase. (d) Area fraction analysis of the austenite phase. 

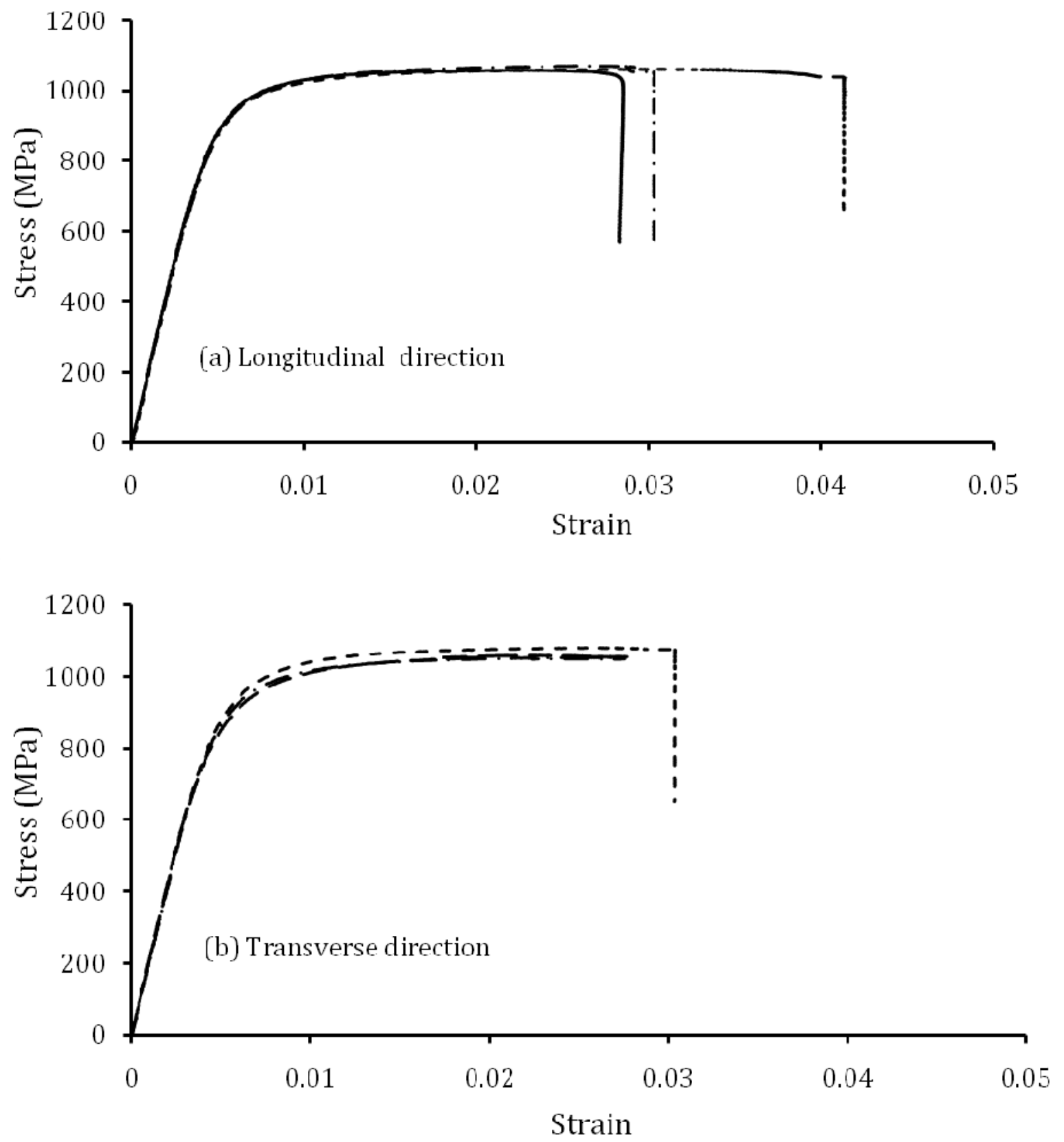

Figure 5 Uniaxial stress - strain response at room temperature, $\sim 22^{\circ} \mathrm{C}$.

(a) Longitudinal direction and (b) Transverse orcircumferential direction. 

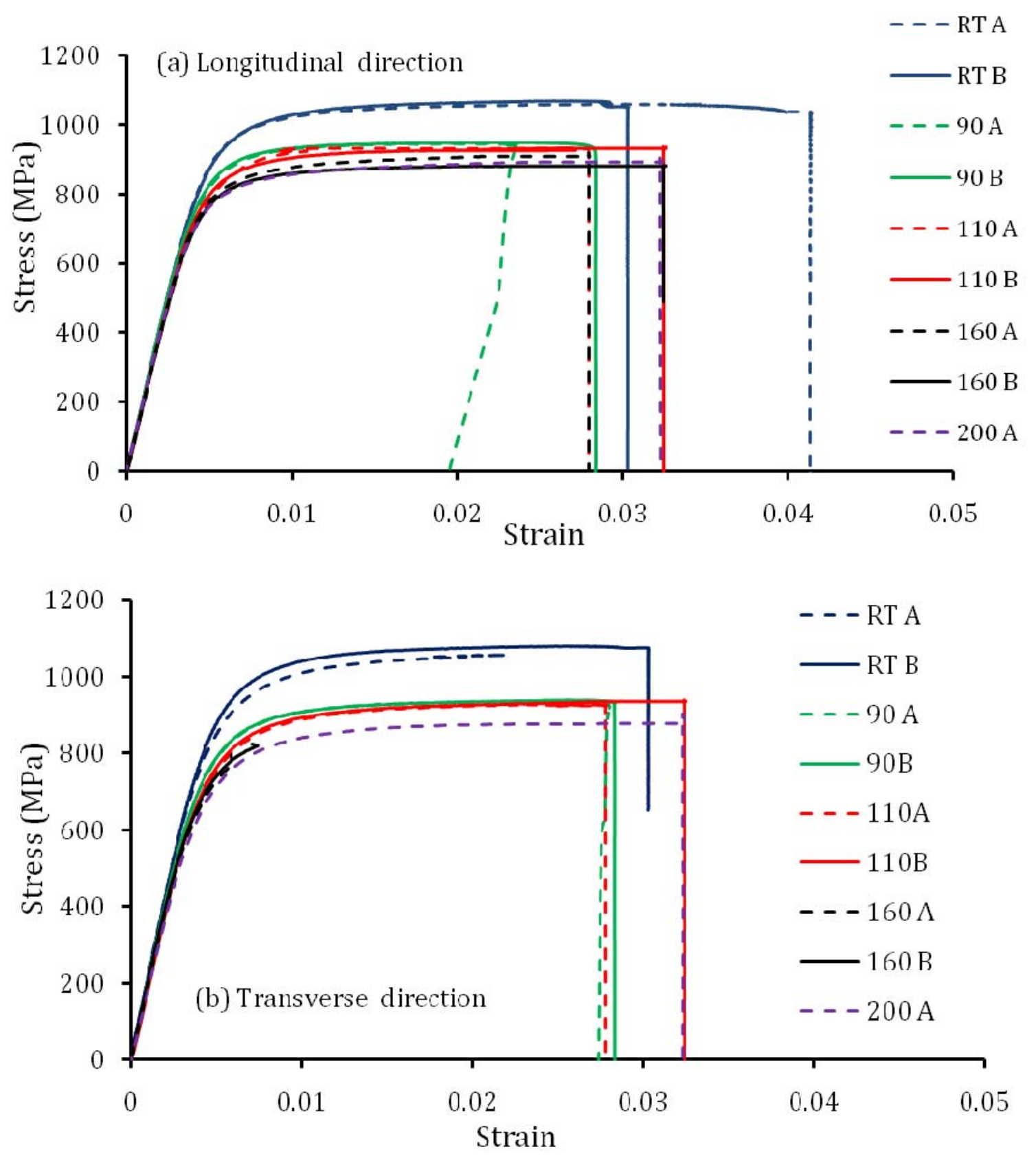

Figure 6 Effect of temperature on the uniaxial stress - strain response

(a) Longitudinal direction and (b) Transverse direction. Two nominally identical specimens tested are identified by letters A and B after the test temperature. 


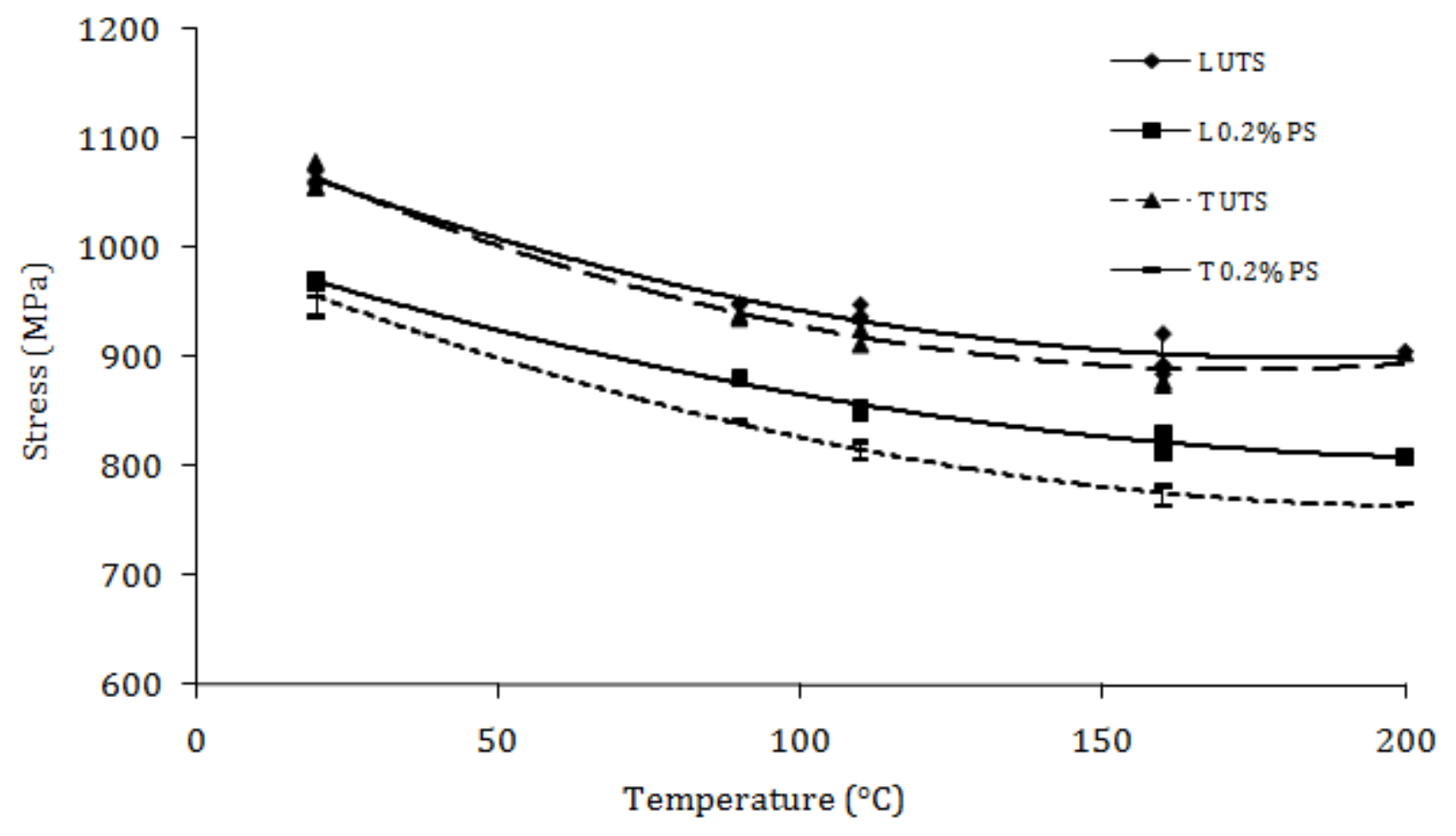

Figure 7: Effect of temperature on the tensile strength (UTS) and 0.2\% Proof Stress (PS) in the longitudinal (L) and transverse (T) directions. 


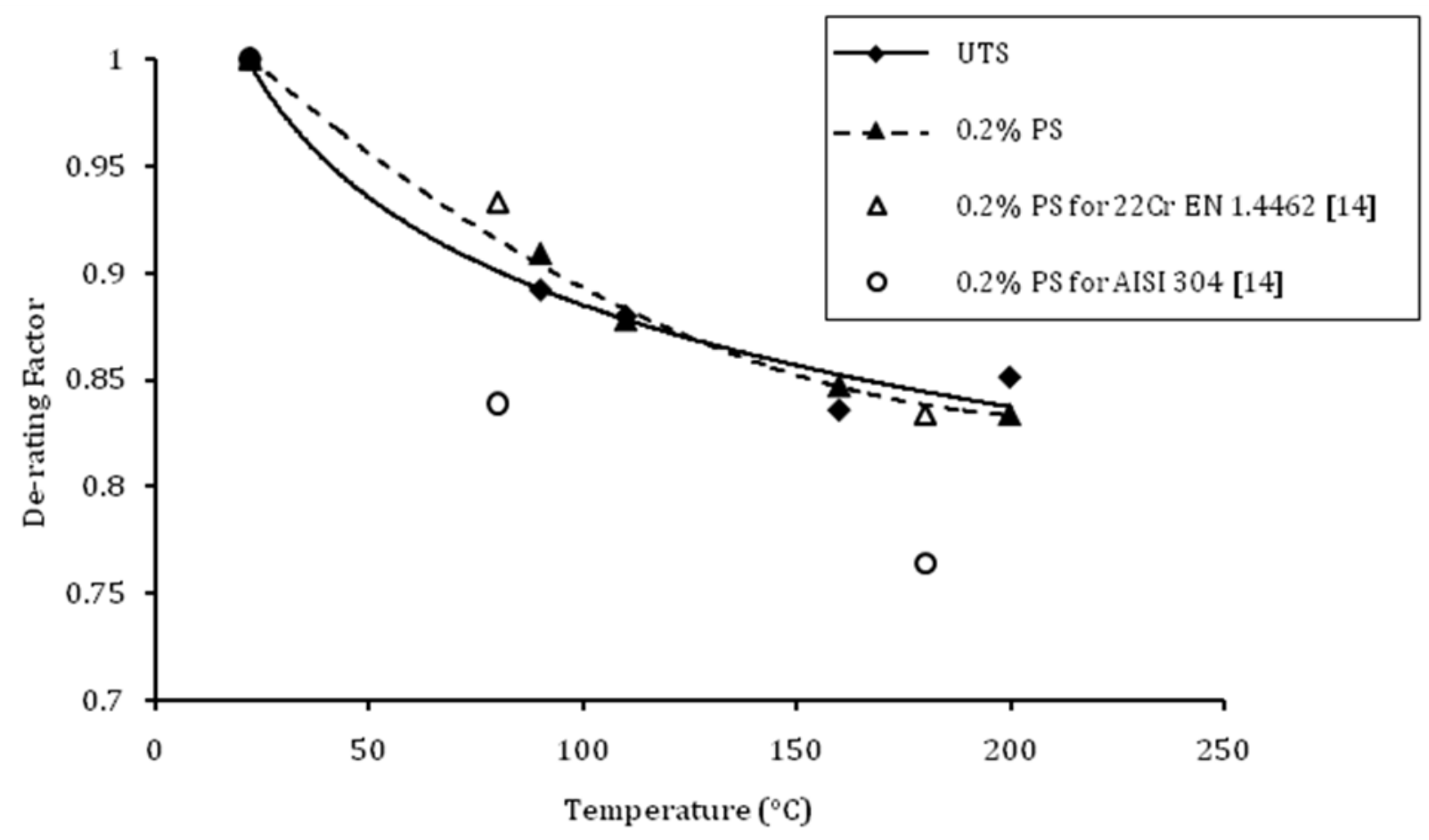

Figure 8: Effect of temperature on the strength de-rating factor, i.e. ratio of the strength UTS or $0.2 \%$ PS at temperature and the value of the corresponding strength at room temperature. The best fit to the experimental data is shown as continuous and dash-dash lines. 